\title{
Research Methods Made Simple
}

\author{
Bhagyashree Deshpande, Anuradha Girme
}

\begin{abstract}
The present article deals with the principles of research methods. The authors have tried to make the steps of research very simple. Many a times a person is unable to understand as to what should be done and how to conduct a research. In the forthcoming pages the researcher has tried to elucidate the steps of research. The researcher has to identify his research area and then he has to proceed to the formulation of the problem statement. Further the most important aspect is to formulate the objectives because the objectives are considered to be the soul of the research. The concepts should be identified before and so also the research design should be formulated. The tools of data collection should be selected in accordance with the nature of research. The selection of the sampling technique should be accurate and precise to avoid the sampling error. Once the data is collected, it should be classified arranged and analyzed. Later it should be interpreted in order to draw interpretation and should be concluded along with suggestions.

Key Words- Problem statement, Hypothesis, Research design, Tools of data collection, Sampling technique, Analysis of data, Report writing. Research methodology followed The doctrinal method of research is followed along with the analytical and descriptive method.
\end{abstract}

\section{INTRODUCTION}

'Research methodology'- the very term generates a sense of complexity and is regarded as difficult subject to be understood in its principles and percepts. Hence the present author had made an attempt to simplify some of the principles of research methodology. It is extremely important to understand and inculcate the percepts of research methodology; because without knowing what to do and how to do; how can any research student conduct or even begin a research project?

The present article deals with the explanation or elucidation of the steps which are to be followed in a research project. With the above objective in mind, the present researcher proceeds further to identify the essential or major steps of research,

The meaning of the term research methods; is the way or the procedure of conducting research. ${ }^{1}$ Any researcher who wants to conduct any research has to follow a particular and precise procedure. For the research to be authentic and fruitful it is mandatory to follow the prescribed methods of research. The moment the student is asked to follow the principles of research, he faces difficulty i.e. what is to be followed and how to follow or incorporate it? Here one has to remember that for any action to be take one has to follow the required or appropriate procedure or process. Always remember that, when the appropriate prescribed procedure is followed then, the possibility of making an error in

Revised Manuscript Received on April 12, 2019.

Dr. Bhagyashree Deshpande, I/C Principal, Bharati Vidyapeeth (Deemed to be) University, NEW Law College, Pune. India (E-mail: Drbdeshpande@nlc.bvdu.in)

Anuradha Girme, Assistant Professor, Bharati Vidyapeeth (Deemed to be) University, NEW Law College, Pune. India. (E-mail: Anuradhagirme@gmail.com) achieving the resultant (end products) is reduced to a very considerable minimum chance. When the researcher follows the principles of research methodology, the chances of committing an error reduces and the chance of the research being authentic increases considerably.

It is to be always remembered that, it is the procedure or the method which is followed to do any act; makes that act wither complete or incomplete or perfect or imperfect. To put it in other words, it is the method which is followed or adopted, which makes the act or the research project successful and authentic or not. This means that the researcher has to follow a particular, prescribed method in order to get authentic resultant of his research. The method of the research and the objectives to be achieved of the research are proportionately related i.e. the more exact and appropriate method adopted, will give the more exact, appropriate and authentic results of the research. Hence it becomes absolutely mandatory to follow the appropriate method while conducting research. Now, let us turn our attention towards this appropriate method of research. For all the social sciences researches the scientific method of research has been prescribed. Law is included in social sciences and hence for all legal associo-legal researches, it is imperative for the researcher to follow the scientific method ${ }^{2}$. The steps involved in a research project which are based upon the scientific method are as follows.

\section{Selection of the topic of research:}

First and foremost the researcher has make up his mind as to in which stream of knowledge he would like to do research. For example, whether he is interested to do research in the branch of law or sociology, or psychology, or political science or economic etc. Once the researcher is firm that he would like to do research in the field of say law, then one can say that the researcher has got hold of $1 / 10^{\text {th }}$ of the direction in which he is going to do research. Sometimes the researcher is of the opinion to do research in more than one field, for example sociology and law; such a research is classified as inter-disciplinary research. When the research topic falls in the scope of two or more streams of knowledge, than such as research is called as inter disciplinary research.

After completion of this step, the next step for the researcher is to select the area of research from the entire subject or discipline. For example, the researcher chooses to do research in the branch of law, then he has to choose the are or field of law like criminal law, jurisprudence, family law or law of contract or torts etc. Once the researcher has made up his mind, and has selected the area; he has to move further and select a topic from the area choosen. It is obvious that he cannot conduct research on the entire 
criminal law or jurisprudence or family law. The researcher has to choose a topic from the selected area. i.e. for example in the case of criminal law; 'rights of the accused' or principle of strict liability. If the choosen subject is family law then the topic of research may be 'reasons for the increasing rate of divorce' or 'the changing trends of the concept of family' etc.

So the focus of research has to be narrowed down from the branch of knowledge- i.e. law, to the subject- i.e. criminal law to the topic rights of the accused.

\section{Formulation of the problem statement.}

The problem statement is regarded as the opening point of the research. To put it in other words, the research starts or begins with the problem statement. The whole research is conducted with the basic objective to solve the problem, and hence it is said that the formulation of the problem statement is the starting point of the research. As the research problem is regarded as the opener, it reflects or indicates the following aspects:

a. What is the area of the research?

b. What is the theme of the research?

c. The objectives of the research

d. It is considered to be the indicator or the mirror of the research.

Hence the researcher should take much efforts to formulate a clear, definite, concise precise and telling statement problem. The research problem is capable of speaking in volumnes of the research.

\section{Statement of the objectives.}

This step is considered as the heart of the research. The value of the research depends upon the objectives is seeks to achieve. So the researcher has to remember to identify very weighty objectives. So also the objectives should reasonable, rational, practical and useful. The researcher cannot afford vague, mythical, mystical or unreasonable because otherwise it will end up in making the research futile.

An important fact is this that, the purpose or the reason for the researcher to conduct the research is to achieve the objectives. Hence the objectives of the research are considered like the main hook of the umbrella under which the entire research spreads or opens up.

The objectives should be :

a. Related to the statement problem.

b. Should be identified in a manageable number i.e. the objective should not be in large numbers.

c. Should be useful or fruitful in furthering the knowledge or the progress of the society. The extent of merit of the objectives results in a meritorious research.

\section{Identify the hypothesis}

Hypothesis means a tentative solution to the formulated research problem. In fact the statement problem and hypothesis are the two sides of the same coin, as both are co-related to one another. The hypothesis is dependent upon the research problem. When the researcher formulates the research problem, then he also has a guess or hunch or idea of the affordable solution to the problem. This idea, guess or hunch is regarded as hypothesis.
The hypothesis should be

a. Even if it a hunch or idea, it should be practicable or feasible.

b. It should be in consonance or matching to the research problem.

\section{Conceptual clarity}

The next step in the research work is to identify the terms and concepts which are considered to be key words, in the research work. After identification, the researcher has to state the meaning of all the key words.

This step is necessary to avoid diverse interpretations of the key words used in the research work. The reader has to understand the same interpretation of the terms which has been already elaborated by the researcher. Conceptual clarity not only makes the reader understand the research in a better manner, but it also develops a sense of same thought angle of the reader and the researcher as far the concepts are clear, it automatically tends to make the research work clear and devoid of ambiguity and vagueness.

\section{Research Design}

Research design means the proposed plan of the research project. This step is regarded as the backbone of the research work. It guides and directs the researcher to proceed in the research project as per the research plan or the research design. Before embarking on actually conducting the research work, the researcher has to plan or chalk out the frame work according to which he wishes to conduct his research. Once the researcher is clear with his plan of how he is going to conduct the research, then he can smoothly, effectively and fruitfully conduct is research. Actually and ideally the research design contains all the steps of research right from the introduction till the conclusion ${ }^{3}$.

The researcher has to decide before hand as to what would be the scope of research, the nature of research, the sources of data, the sampling techniques to be employed, the system of analyzing, coding and decoding and how data will be inferred and interpreted. The researcher has to comprehend and visualize the minutest details and then formulate the research design. If the researcher incorporates the minutest details in the research design, then obviously it will not only be easy for the researcher, but also the research will be more systematic. The more accurate, precise, detailed and particular research design will procure more accurate authentic and fruitful research.

If the research design is well formulated then

a. It makes the research systematic and scientific

b. It gives the researcher a direction to proceed in his research work.

c. It saves the researchers time, energy and money, as he has in his research plan ready, he knows what, how, when and why he has to be next in the process of research work.

d. Accurate and detailed research design, helps in enabling the researcher to finish is research in the prescribed time limits. 
It is to be noted that there are two aspects to ensure a fruitful authentic research. One to formulate a very accurate and detailed research design; and the other is to meticulously follow the prepared research design.

\section{Tools of data collection}

The researcher has to identify the tools of data collection prior to the commencement of the research project. There are two sources from which the relevant data can be collected.

a. Primary sources of the data collection

b. Secondary sources of data collection

When the data is collected for the first time from a particular source, such a source is classified as a primary source of data.

If the source is already used and the researcher reuses the such a data for the second or many other researcher have used the data; then such a data is classified as secondary data.

Primary sources of data can be enumerated as interview technique, questionnaire and observation. Secondary data include test books, journals, articles, newspapers, internet etc.

Tools of data collection are very important because the nature of research depends upon types of tools of data employed to collect the data of the research. If the primary sources of data collection are used, then such a research is classified as a non-doctrinal or empirical research; where as if the secondary sources of data are used then the research is classified as a doctrinal or arm chair research.

\section{Sampling techniques\& Analatical Results}

There are two types of sampling techniques applicable to the non-doctrinal research.

a. The Probability or the simple random sampling technique.

b. The Non probability or the non-random sampling technique.

In case of probability sampling technique, each and every of the research enjoy an equal probable chance of being included in the research. Whereas in the non probable sampling technique, every element does not enjoy an equal chance of being selected in the sample.

The simple random sampling or probability includes the systematic sampling technique, lottery method. The non probable sampling includes the purposive or judgmental, accidental sampling technique.

\section{Analysis of data}

After the data is collected from the samples, the data has to be arranged for the purpose of classification.The criteria to be used for the arranging and classification of data should be used related to the objectives of the research.

The classification and arranging of the data is done in order to be able to interpret the data and the data is interpreted in order to fulfill the objectives of the research or for the purpose of proving or disproving the hypothesis. Hence the researcher has to be very particular, precise and specific in selecting the criteria to classify the data.

Apart from the specific criteria of classification, general criteria of time may also be applied. The criteria of time includes weeks, months or year i.e. for examples data can classified on the basis of a year or month. That is in the year 2018 a particular data existed and in the year 2019 a different data prevails. When the time criteria is utilized the researcher is also able to ascertain the development of a aspect of the concerned research. Another general criteria for the classification may be the answer which may be answered in the positive or the negative.

After the classification, the data has to be arranged according to the criteria which are used for the classification.

After the arrangement of data, the researcher has to interpret and analyse the said data.

Once the data is analysed, the researcher has to draw conclusion with reference to the interpretation and analysis of the data. The conclusions are to be drawn on the basis of the analysis. In the conclusion the researcher also has to state whether the objectives of the research have been fulfilled, and has to forward the solution to the problem. Later he also has to recommend some suggestions regarding his research aspects.

\section{Report writing is the last step of the research project.}

The researcher after the completion of the entire research has to write a report which comprises of the entire research activity. For example how the steps of the research programme were formulated as well as implemented by the researcher. Had the researcher received any valuable help or did he face any problems while he conducted his research project. The report writing helps the other research scholar as it gives an idea of actually conducting the research.

\section{CONCLUSION}

Research work is considered to be a very complex task and it requires expertise and creativity on the part of the researcher. The researcher has to identify the area of the research well and also the problem statement. Each and every step, from the formulation of the problem to the report writing, the researcher has to plan before he embarks upon conducting the research. Only then the researcher is able to carry out his research work objectively and authentically. This planning of research i.e. the research methodology plays a vital role because the method makes the research fruitful and authentic.

\section{REFERENCES:}

1. Abrahamson, Mark, Social Research Methods, Englewood Cliffs, N,J: methods, Englewood Cliffs, n. j: Prentice-Hall Inc, 1983.

2. Barber, Steve and Mark A McCormick, Legal Research, New York: Delmar Publishers, 1996.

3. Bast, Carol and Margie Hawkins, Foundations of Legal Research and Writing (Second ebn) ,New York: Thomson Learning, 2000.

4. Burgess, Robert G(ed), Field Research: A Sourcebook and Field Manual, London: George Allen and Unwin, 1982.

5. Campbell ,Enid, Lee Poh -York and Joyce Tooher, Legal Research: Materials and Methods (Fourth edn),Sydney: LBC Information Services, 1996

Blue Eyes Intelligence Engineering

\& Sciences Publication 
6. Chava Frankfort- Nachmias and David Nachmias, Research Method in the Social Sciences (Sixth edn) New York: Worth Publishers, 2000.

7. Sarda, M., Deshpande, B., Deo, S., Karanjkar, A comparative study on Maslow's theory and Indian Ashrama system, International Journal of Innovative Technology and Exploring Engineering ,2018

8. P. L. Bhandarkar and T. S. Wilkinson, Methodology and Techniques of Social Research, Himalaya Publishing House, $23^{\text {rd }}$ Edition.

9. Chuah, Molly and Chan Sai Noi, Looking Up Malaysian Law: Legislation And Law Reports, Kuala Lampur: University of Malaya, 1987.

10. Foster, Uwe, An Introduction to Qualitative Research, Thousand Oaks CA: Sage Publication, 1998.

11. Sarda, M., Deshpande, B., Dharm, J., Dhere, V., Different aspects of environmental laws , International Journal of Recent Technology and Engineering, 2019

12. Eckhardt, Kenneth W and David Ermann, Social Research Methods, New York, 1997.

13. Gifford, D J and John Salter, How to Understand an Act of Parliament, London, Cavendish Publishing Limited,1996.

14. Smith, David J, Legal Research and Writing, New York: Delmar Publishers, 1996.

15. Statsky, William P, Legal Research and Writing: Some Starting Points, (Fifth edn), New York: Delmar Publishers, 1999.

16. Sarda, M., Deshpande, B., Shringarpure, S., Smart city - Use of technology and the needed labor reforms, International Journal of Innovative Technology and Exploring Engineering ,2018

1. ${ }^{1}$ See Kaufmarn Felix; Methodology of Social Sciences; (1944) W\&B P.43

2. ${ }^{2}$ Bhandarkar \& Wilkinson; Methodology and techniques of social Research.' (2010) p.p. 1-44.

3. $\quad{ }^{3}$ Infra, p. 